\title{
Sexual dimorphism and geographical male polymorphism in the ghost moth Hepialus humuli (Lepidoptera: Hepialidae): Scale ultrastructure and evolutionary aspects
}

\author{
Svend KAABER ${ }^{1}$, Niels P. KRISTENSEN $^{2, *}$ and Thomas J. SIMONSEN ${ }^{2, * *}, * * *$ \\ ${ }^{1}$ Natural History Museum Aarhus, Universitetsparken, DK-8000 Aarhus C, Denmark; e-mail: svend@kaaber.net \\ ${ }^{2}$ Natural History Museum of Denmark (Zoological Museum), University of Copenhagen, Universitetsparken 15, \\ DK-2100 Copenhagen Ø, Denmark; e-mail: npkristensen@snm.ku.dk
}

Key words. Hepialidae, Hepialus humuli, wing length, wing-scale structure, bird and bat predation, predatory selection, prey visibility, polymorphism, sexual dimorphism, Faroe Isles, Shetland Isles

\begin{abstract}
Throughout most of its range the Palaearctic moth Hepialus humuli shows a striking sexual dimorphism correlated with a dimorphism in wing scale ultrastructure. Male uppersides are uniformly silvery white, due to light reflection from unpigmented scales with an elaborate internal cuticular meshwork; the conspicuous wings are visual cues for females when lekking males swarm at dusk. Female uppersides have a yellow-and-orange pigment pattern, and commonplace scale morphology. Male specimens from the Shetland and Faroe Islands populations are polymorphic, with wing uppersides ranging from the typical uniform white to being patterned much as in females, or even more melanic; forewing length is slightly greater in the darker and patterned male morphs. Male wing-scale polymorphism is only modest: even the superficially most female-like specimens are overall similar to typical males with respect to important details of scale structure. The polymorphic N. Atlantic forms are likely derived from dimorphic ancestors of the continental type. The principal selective force favouring male darkening in these insular populations is most probably a locally strong predation by visual hunters (primarily gulls and terns) on the lekking moths, combined with a lessened importance of the colour-related conspicuousness of males for female mate-searching at the high ambient light level at the swarming time at these high latitudes. This assumption is supported by the finding of a higher abundance of cryptic males (and perhaps by the smaller average size of the non-cryptic male morphs) in sites with intense bird predation.
\end{abstract}

\section{INTRODUCTION}

The widespread and common West Palaearctic ghost moth Hepialus humuli (Linnaeus, 1758) shows a marked sexual dimorphism throughout most of its range: males have silvery white fore and hind wing uppersides, while female fore wings are yellowish with an orange spot pattern (which may be greatly reduced and occasionally entirely lost; see illustrations in Freina \& Witt, 1990). Female hind wing uppersides, and the undersides of both sexes, are unicolorous grey-brown. Male $H$. humuli, like males in certain other hepialid genera (review in Mallet, 1984), form lekking swarms at twilight. It is to the sometimes dense aggregations of white "pendulating" males of this species that it (indeed the entire family Hepialidae) owes the name "ghost moth".
It has long been known that the populations of $H$. humuli on the Faroe and Shetland Isles**** in the North Atlantic have remarkably polymorphic males: their forewing patterns range from being similar to that of mainland British/continental males to being similar to that of continental females (though with the forewing markings more brownish), and even more melanic than the latter; the females differ little from those of typical $H$. humuli, although they too may have more brownish markings and a somewhat darker forewing ground colour (see, e.g., Heath, 1976; Skinner, 1984; de Freina \& Witt, 1990; Majerus, 1998). The Shetland population was described as subspecies $H$. humuli thulensis Newman, 1865 (syn. hethlandica Staudinger, 1871), while the Faroe population has been named $H$. humuli faeroensis Dahl, 1954; however, a taxonomic distinction between the two

\footnotetext{
* Corresponding author.

** Present address: Department of Biological Sciences, CW405, Biological Sciences Centre, University of Alberta, Edmonton AB T6G 2E9, Canada.

$* * *$ Author sequence is alphabetical.

****British authors (e.g., Ford, 1955; Lorimer, 1983) have expressly stated that female-like male morphs are absent from the Orkney Isles. The statement of de Freina \& Witt (1990: 67) that the thulensis form occurs in the Orkney Isles is surely due confusion caused by mislabelled specimens and/or misinterpretations of labels; they illustrate (Plate 10, Fig. 17) a thulensis male allegedly from "Orkney-Inseln, Unst", but Unst is one of the Shetland Isles. The statement in the same work (p. 66) that the nominate subspe-

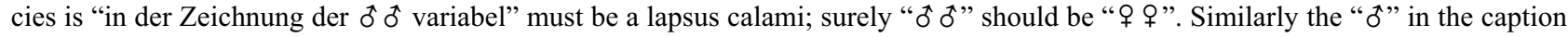
of their Plate 10, Fig. 4 should be "o".
} 
appears little meaningful, and they were justifiably synonymized by de Freina \& Witt (1990).

The aberrant male colouration in these N. Atlantic populations has understandably attracted repeated attention. Hoffmeyer (1948/1960) stated the belief that the female-like N. Atlantic males "apparently [åbenbart] are the original/ancestral [oprindelige] form". Ford (1955) related their occurrence to the high ambient light intensity during the swarming hours at these high latitudes, a line of inquiry pursued at greater depth by Hansen \& Jensen (2005), who considered the male polymorphism in the context of sexual selection as well as predation pressure from birds; the latter authors also documented a notable geographical variation in male morph frequencies within the Faroe archipelago.

The focus of the present contribution is on wing scale structure and the phenotypical variation in the male sex. The brilliant, silvery white colour of the nominotypical male upperside would be expected to prove to be due to light reflection from a specialised type of wing scales, since it disappears rapidly when wings are immersed in a fluid fixative or embedding medium; it similarly disappears in "greasy" wing areas of collection specimens. We here describe the wing-scale structure in the sexually dimorphic continental $H$. h. humuli. We then address the question of how the macroscopical polymorphism in male $H$. humuli thulensis is related to scale structure and also to wing size, since our preliminary observations (as well as illustrations in British treatises such as South, 1961; Kettlewell, 1973; and Skinner, 1984, but not Ford, 1955) suggested that the dark male morphs are on average slightly larger than the light ones. Finally we consider the relevance of the results for the question of the ancestral/derived status of the N. Atlantic female-like male morphs and link this to a succinct review of the evidence, largely presented in previous work, which bears on the evolutionary background for the polymorphism.

NPK made the initial SEM and TEM observations on nominotypical $H$. humuli which disclosed the sex differences and the unusual configuration of male upperside scales; he subsequently suggested to TJS a more detailed study of the scale structure, extended also to the distinctive Faroe populations, and he undertook much of the definitive manuscript revision. TJS contributed the bulk of the morphological descriptions/illustrations and drafted the initial version of extensive text sections. SK contributed field information on the moths' behaviour as well as on bird predation in the Faroes and Shetland; he also measured (jointly with TJS) forewing lengths of $H$. humuli thulensis from the said islands in the two Danish museum collections and processed these data.

\section{MATERIAL AND METHODS}

We examined and measured all N. Atlantic male material of $H$. humuli in the two Danish natural history museums, comprising 72 (Copenhagen) and 423 (Aarhus) male Faroe specimens, and 22 (Aarhus) Shetland specimens, respectively; in addition 174 female Faroe specimens (Aarhus) were measured. The length of the right forewing was used to characterize the general size of the male morphs in $H$. humuli thulensis. The length of the forewings was measured with the use of the pointed ends of a spreading Vernier calliper with a reading accuracy of $0.05 \mathrm{~mm}$. The error of the method, s(i), between TJS and SK was calculated using duplicate measurements of a group of 25 male specimens. The s(i) value was $0.48 \mathrm{~mm}$. Calculations were made with the SYSTAT programme 12 for Windows $@$.

The general characteristics of the wing vestiture were examined at high magnification in a Leica ZM APO dissecting microscope, using different angles of illumination (transmitted light is particularly informative). Dorsal wings scales from both fore and hind wings of one female and one male of H. humuli humuli from Denmark and one female and six males of $H$. humuli thulensis from the Faroes were examined in a JEOL JSM-840 scanning electron microscope; adwing scale surfaces were exposed by pressing scale-covered wing fragments onto doubleadhesive tape on the SEM stubs and subsequently gently lifting the wing membranes away. The dorsal wing scales of the same specimens were examined in a JEOL JSM 100SX transmission electron microscope (TEM) for internal structures, using a method which earlier proved useful for study of lepidopteran scales: scales were placed on a droplet of distilled water on a parlodion-film covered 50 mesh grid, to which they adhered after evaporation of the water. In addition, ultrathin transverse sections of dorsal fore-wing scales of one male $H$. h. humuli and one male $H$. humuli thulensis were examined. Two of the examined male specimens of $H$. humuli thulensis represent types 1 and 2 (as defined below) respectively, while four represent "type 3"; the sectioned scales were from a type 3 specimen.

Only dorsal wing scales are treated in this study, since neither macroscopic nor microscopic dimorphism or polymorphism was observed in the scales on the ventral wing surfaces. All ultrastructural examinations were on scales located in the central or subapical part of the wing.

The scale nomenclature of Downey \& Allyn (1975) and Kristensen \& Simonsen (2003) is adopted; in particular it may here be noted that the term "secondary ridges" refers to the less numerous large ridges in scale types which exhibit ridge size dimorphism.

\section{RESULTS}

\section{Wing pattern and scale diversity}

Lepidoptera scales are very diverse formations. Several types co-exist on the same wing, and while their shape and other structural features may be correlated with their colours as well as with their position on the wing, it must be emphasised that even scale assemblages in the same area, with the same colour (and, in male H. humuli thulensis, of the same broad "type"; see below) may differ from one specimen to the next in such characteristics as frequency of strong dentition etc. For this reason some reservation must be made with respect to our generalisations from the necessarily limited number of electronmicroscopy examinations on scales in the different morphs.

The following account focuses on the lamellar wing surface scales. All specimens have scattered piliform scales along the principal longitudinal veins.

\section{Female Hepialus h. humuli (Figs 1, 2, 5)}

Most fore-wing scales are ovoid-lanceolate (Fig. 2A), those of the orange spots are on the average narrower and more pointed than those of the yellow ground colour. The 


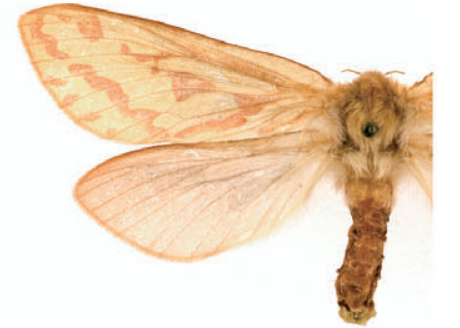

A

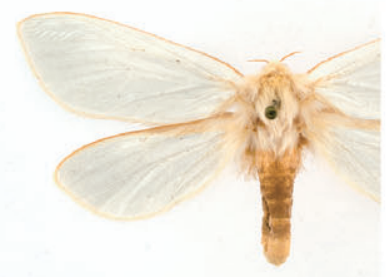

B

$20 \mathrm{~mm}$

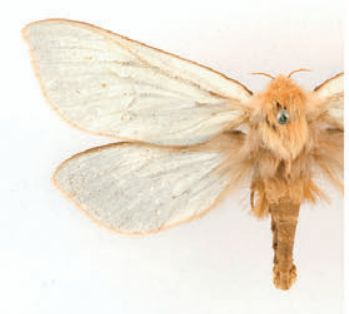

C

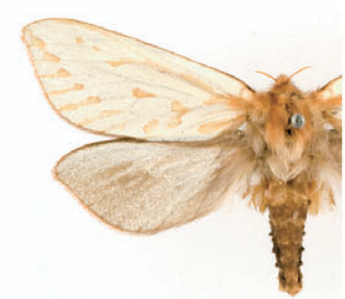

D

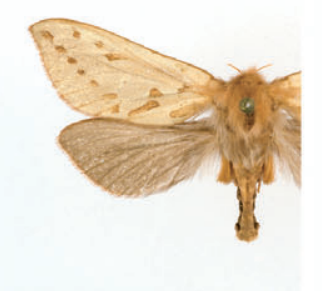

E

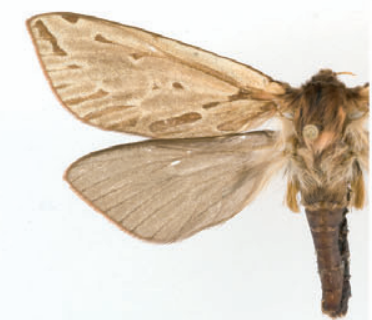

F

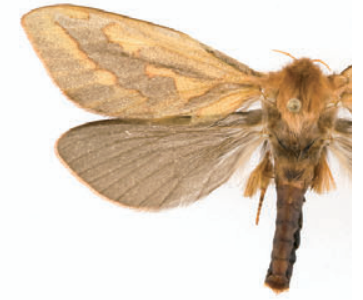

G

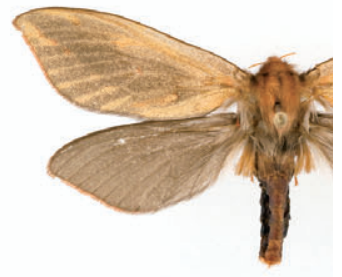

$\mathrm{H}$

Fig. 1. H. humuli, habitus. A-B: H. h. humuli (Denmark); A - female, B - male. C-H: H. humuli thulensis males (Faroes); C "type 1", D - "type 2"; E-H - morphs grouped as "type 3", including unusually darkened specimens of the Sandoy population (G, $\mathrm{H})$.

scale apex is most often produced into a single blunt point, but some scales of both colours have the apical margin dentate. Near-parallel-sided scales with dentate apical margins are prevalent along the anterior and apical margin, and the very elongate marginal scales ("cilia"/"fringes") themselves are also of this kind. Scales of both colours have more or less strongly developed $2^{\text {nd }}$ order ridges (sr) on the abwing surface (Fig. 2B); between the primary ridges (pr) are ordinary crossribs (cr), and windows which may be "normal" (w) or reduced/vestigial (vw), i.e., not perforated, just identifiable as delicate featureless cuticle. On the adwing surface of the yellow scales the ridges are very weakly developed and there is no sculpture on the adwing surface of the red scales (Fig. 2C). The TEM shows that the trabeculae (tb) between the abwing and adwing lamellae are scattered and simple (Fig. 5A).

The hind-wing scales are narrow and elongate, with 3-5 apical teeth (at) (Fig. 2D); they do not form a closed covering. Their abwing surface bears primary ridges, secondary $/ 2^{\text {nd }}$ order ridges ( $\mathrm{sr}$ ), windows, reduced windows and crossribs (Fig. 2E). On the adwing surface there are weakly developed primary ridges, crossribs and reduced windows on the apical half of the scale (Fig. 2F). As in the fore-wing scales the trabeculae are scattered and simple (Fig. 5B).

\section{Female Hepialus humuli thulensis}

The fore-wing scales are similar to those of female $H$. $h$. humuli in overall shape and in the structure of the abwing surface. The trabeculae are developed as in female $H$. $h$. humuli.

The hind-wing scales are similar to those of female $H$. h. humuli (also in trabecular development), except that the primary ridges on the adwing surface continue to the base of the scale.

\section{Male Hepialus h. humuli (Figs 1, 3, 5)}

The cuticular walls of the white scales are entirely colourless, and the scales are not easily examined by conventional brightfield microscopy of whole mount slide preparations, where the scale lumen is filled with embedding medium. The white fore-wing scales (Fig. 3A) are broader and much more obtuse than the female wingsurface scales, and on the abwing surface (Fig. 3B) windows and crossribs are less numerous than in the latter. Ridge dimorphism is little, if at all indicated. The apical margins of most scales are smoothly rounded or nearly straight, at most very finely dentate/scalloped. However, white scales with $2^{\text {nd }}$ order ridges and markedly dentate apical margins do occur in a zone along the anterior and apical margins as well as along vein R/Rs. On the adwing surface the white scales have distinct primary ridges and crossribs (Fig. 3C). The trabeculae between the abwing and the adwing lamella are extremely numerous and elaborate, forming a complex meshwork (Figs 5C, D, G). 


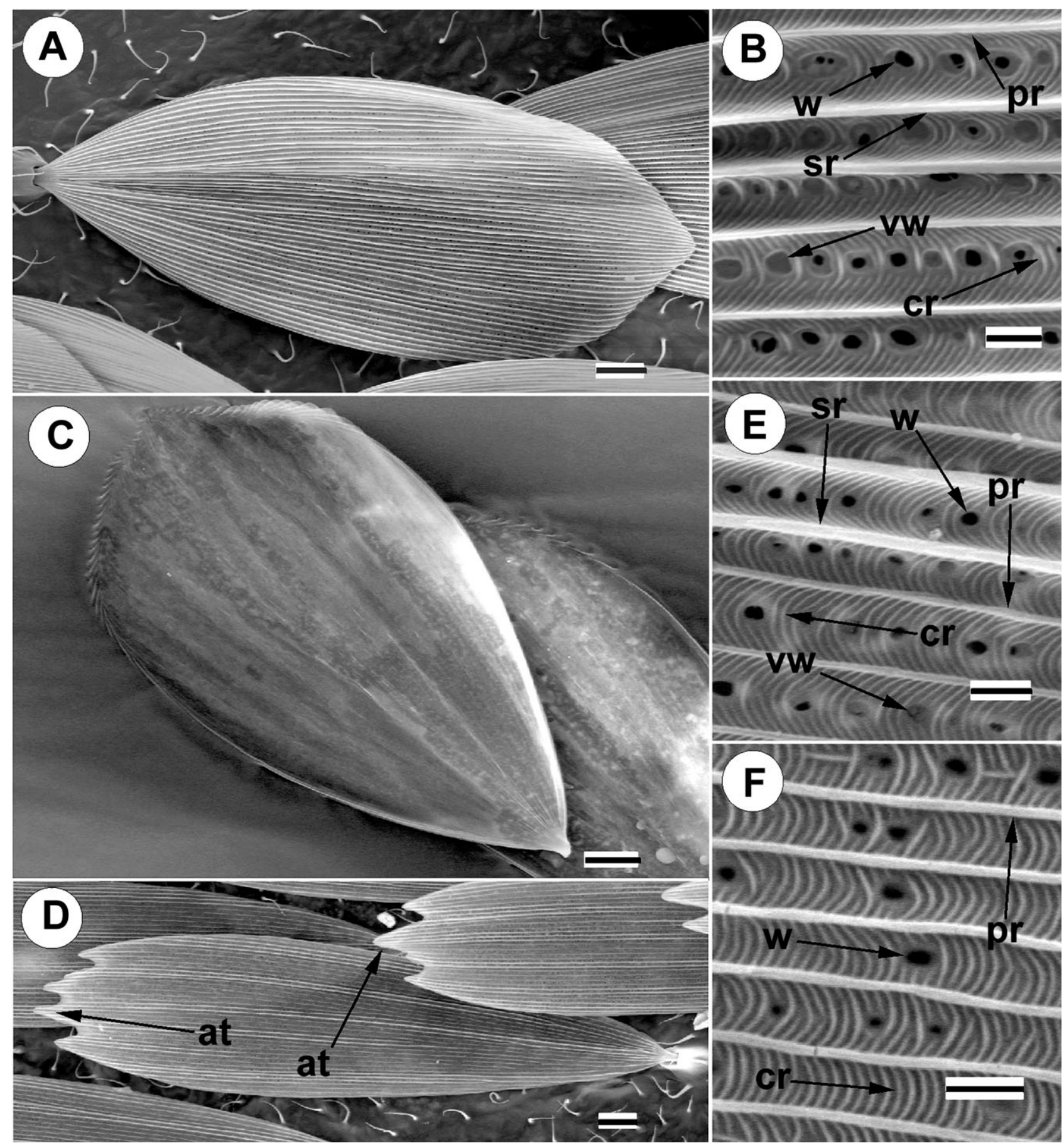

Fig. 2. H. humuli humuli, female scales (SEM). A - forewing scale, abwing; B - detail of A; C - forewing scale, adwing, note absence of sculpture; D - hind wing scale, abwing, note at; E - detail of D; F - detail of hind wing scale, adwing. at - apical tooth; $\mathrm{cr}-$ crossrib; $\mathrm{pr}-$ primary ridge; $\mathrm{sr}-$ secondary $+2^{\text {nd }}$ order ridge; $\mathrm{vW}-$ window vestige; $\mathrm{w}-$ window. Scale bars: $\mathrm{A}, \mathrm{C}, \mathrm{D}=10 \mu \mathrm{m}$; $\mathrm{B}, \mathrm{E}, \mathrm{F}=1 \mu \mathrm{m}$

The orange-brownish scales along the anterior and apical margins resemble their female counterparts.

The hind-wing scale covering is similar to that of the fore wings, except that the individual scales are somewhat narrower; however, they similarly form a dense covering (except on the anterior basal wing area where only long, slender hairs occur).
Male Hepialus humuli thulensis (Figs 1, 4, 5)

Male specimens of the polymorphic N. Atlantic populations are here assigned to three broad categories ("types") on the basis of the upperside wing pattern (cf. Kettlewell, 1973: 295): “Type 1" (Fig. 1C) is almost identical to the continental male, except that the white scales have a slightly less brilliant reflectance. "Type 2" (Fig. 1D) similarly has a white ground colour on both wing pairs, but the reflectance is even duller, and the fore wings have a 

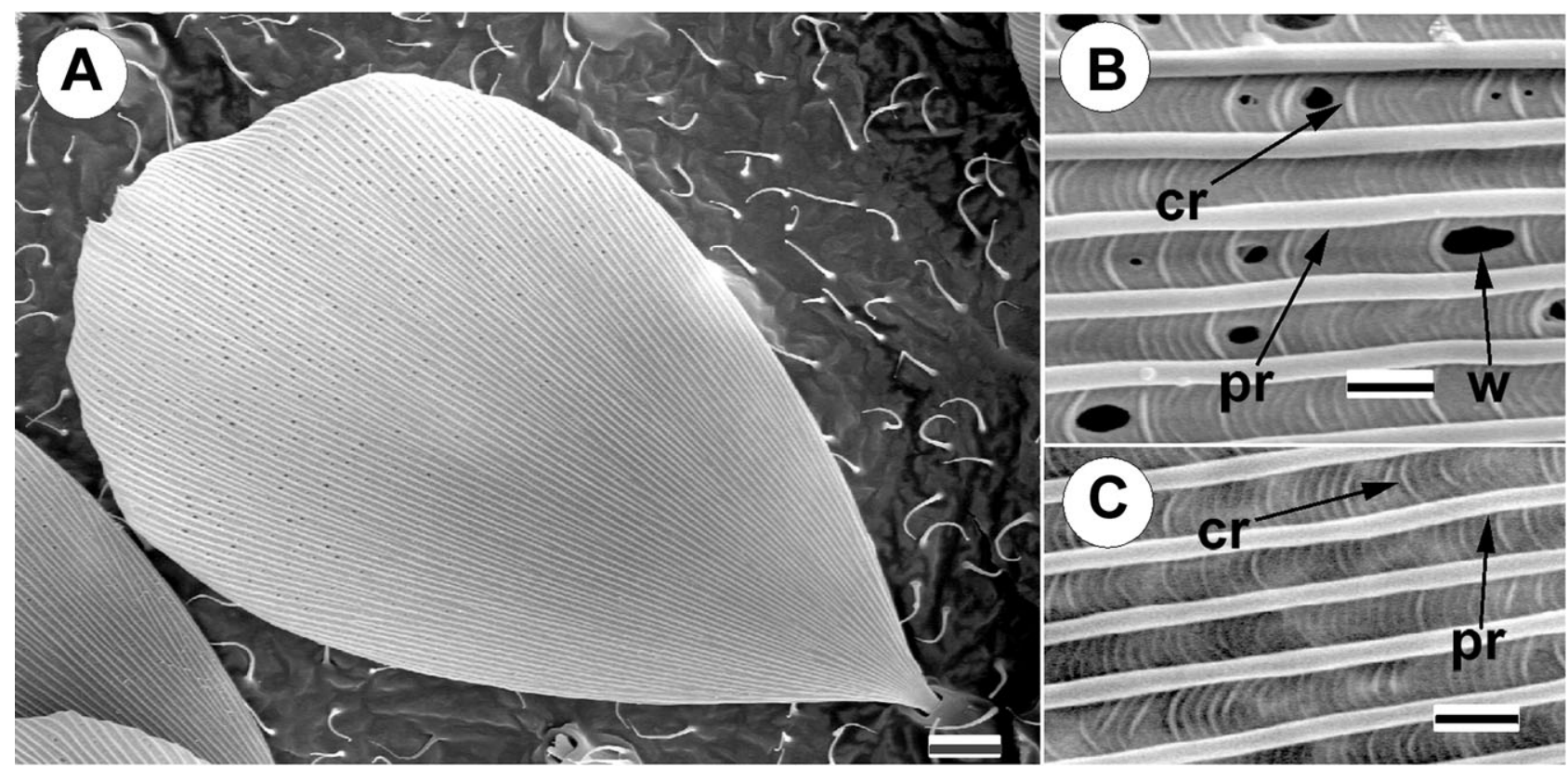

Fig. 3. H. humuli humuli, male scales (SEM). A - forewing scale, abwing; B - detail of A; C - detail of forewing scale, adwing. cr - crossrib; pr - primary ridge; $\mathrm{w}$ - window. Scale bars: $\mathrm{A}=10 \mu \mathrm{m} ; \mathrm{B}, \mathrm{C}=1 \mu \mathrm{m}$.

pattern of reddish-brown spots which may be more or less extensive; as a minimum there are small spots behind $\mathrm{CuA}$ and at the base of the anal field. The hind-wings have a variably developed (sometimes very weak) suffusion of greyish-brown scales. "Type 3" (Figs 1E-H) is overall similar to females, i.e., the fore-wings have a yellowish ground colour with a variably developed (sometimes practically nonexistent) pattern of spots which often are brownish-red rather than orange; the hind-wings are quite dark, uniformly grey-brown.

Not surprisingly, occasional individuals are intermediate between these principal categories, at least between types 2 and 3, and the variability within these two types is considerable. Hansen \& Jensen (2005) adopted a more detailed (5-type) categorisation of male morphs; our type 1 corresponds to their types $\mathrm{LL}+\mathrm{L}$, type 2 to their $\mathrm{LD}$, and type 3 to their types D+DD. Pronouncedly melanic forms (DD of Hansen \& Jensen) of type 3 are overall rare but do occur regularly in some localities on Eysturoy (Dahl, 1954), Sandoy and Nolsoy; such individuals (Figs $1 \mathrm{G}-\mathrm{H}$ ) have the (otherwise still variable) forewing pattern strongly suffused with grey scales, and the hind wings are very dark.

Hansen \& Jensen examined 2,435 Faroe male specimens, and the material examined by us in Table 1 comprises another 495 specimens. Of this total of 2,930 male moths $\approx 32 \%$ are assigned to (our) type $1, \approx 28 \%$ to type 2 and $\approx 40 \%$ to type 3 . However, the proportions vary considerably between samples from different islands, and in some cases between different sampling sites within the larger islands. Random light trap samples taken in Shetland during 1964 showed that only 3 males or $3.9 \%$ were our type 1 , while 18 or $23.6 \%$ were type 2 , and 59 or $77.6 \%$ were type 3 (Kettlewell, 1973). Similar samples taken in 1996 by SK and shown in Table 1 failed to dem- onstrate the presence of type 1 males, while the proportions between type 2 and 3 males were rather similar to the findings from 1964.

Type 1. The scales of both fore- and hind wings are similar to those of male $H$. h. humuli in all aspects.

Type 2. The two colour forms of the fore-wing scales are clearly different. The white scale covering is overall similar to that of the preceding type; examined individual scales have, on the abwing surface, more (but reduced) windows, and more crossribs than those of male $H . h$. humuli. The reddish scales are similar to those of female $H$. h. thulensis, with only very weakly developed primary ridges on the adwing surface.

On the hind wing the greyish-brown scales are often distinctly dentate; they may or may not have secondary $/ 2^{\text {nd }}$ order ridges. Even the white scales among which they are interspersed are sometimes dentate.

In this and the following type both wing-pairs may bear near-parallel scales with secondary $/ 2^{\text {nd }}$ order ridges and marked dentition along some of the longitudinal veins, even if such scales are absent in the adjacent "cells".

Type 3 (Figs 4, 5). As in other male types the groundcolour scales (yellowish and/or greyish) on the fore-wing are broad and apically rounded; there is considerable individual variation in the tendency towards formation of $2^{\text {nd }}$ order ridges and in degree of scalloping of the apical border. The abwing scale surface bears more windows and crossribs than the white scales of male $H$. h. humuli (Fig. $4 \mathrm{~B}, \mathrm{E})$. On the adwing surface the ridges are reduced (absent) in an area close to the apical margin. The rest of the adwing surface has primary ridges and crossribs fully developed (Fig. 4C, D) on most of the studied scales, but the adwing sculpturing is weakly developed on the grey scales from one of the three closely examined melanic Sandur specimens (Fig. 4F). The trabecular meshwork is 

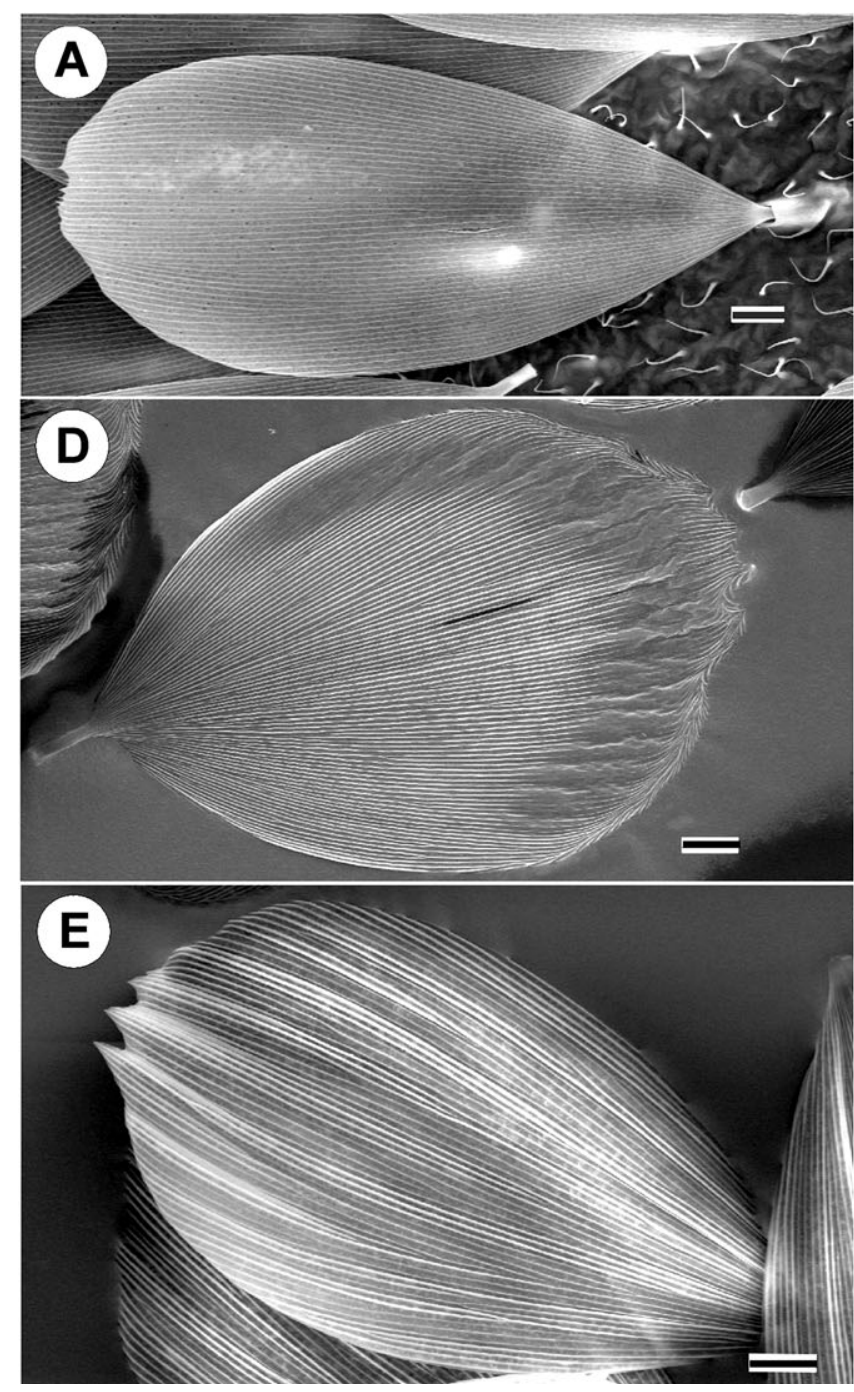

not as elaborate as in male $H$. h. humuli, but still more extensive and complex than the complement of trabeculae in females of both $H$. h. humuli and H. h. thulensis (Fig. $5 \mathrm{E}, \mathrm{H})$. The reddish scales are similar to those of female H. h. thulensis.

As in the other male types the hind-wing scales are considerably broader than in females, forming a complete covering (Fig. 4A). Their outline is variable: they may be truncate, rounded or lanceolate-pointed, and the apical margin may be smooth, scalloped or dentate. Secondary $/ 2^{\text {nd }}$ order ridges are variably developed, but are frequently present only on scales in the anterior/apical marginal zones and on veins. The trabecular meshwork is somewhat elaborate (Fig. $5 \mathrm{~F}$ ), though less so than in male H. h. humuli.

\section{Local polymorphism and size variation in $\mathrm{H}$. humuli thulensis}

The proportional representation of male morphs varies markedly across the Faroe archipelago. The local variation in male morph abundance is shown in Table 1. Due to the markedly unequal sample sizes of different local populations the Faroe material was divided into two groups, one comprising samples from the larger isles and another the three consecutive annual samples from the

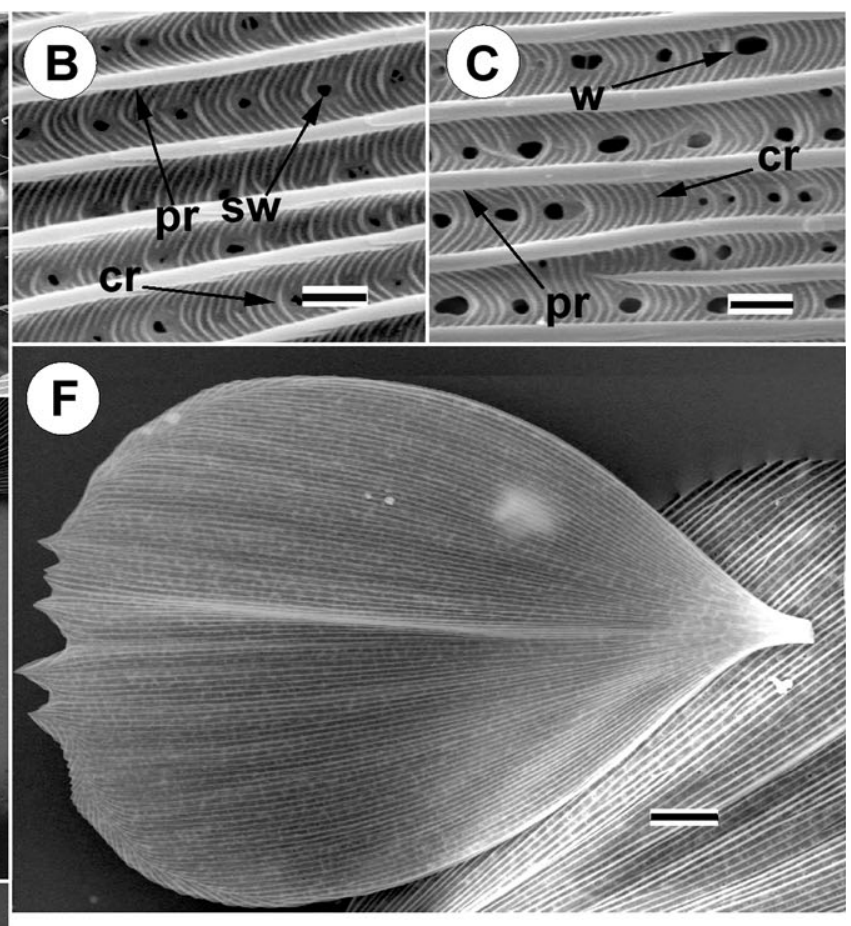

Fig. 4. H. humuli thulensis, type 3 male scales (SEM). A hind wing scale, abwing; $\mathrm{B}$ - detail of red forewing scale, abwing; C - detail of yellow forewing scale, abwing; D yellow forewing scale, adwing, note absence of sculpture close to the apical margin; E - yellow forewing scale, abwing, note small apical teeth; F - grey forewing scale, adwing, note small apical teeth and delicate primary ridges. cr - crossrib; pr - primary ridge; $\mathrm{sw}$ - small window; $\mathrm{w}$ - large window. Scale bars: A, D-F $=10 \mu \mathrm{m} ; \mathrm{B}, \mathrm{C}=1 \mu \mathrm{m}$.

isolated islet of Stora Dimun. A third group comprised Shetland material obtained during field work in 1996. With respect to morph distribution our Faroe data are in broad agreement with those reported (generally on the basis of larger samples) from various sites by Hansen \& Jensen (2005) and mapped (with pie-charts) by these authors. While our modest Shetland sample comprises no type 1 males, this morph accounted for 26 of the 187 Shetland male specimens in the Natural History Museum (London); here 58 type 2 and 103 type 3 males are present.

Table 1 also shows local size variation (as expressed by fore-wing lengths) in Faroe ghost moths. Males of type 1 from the main Faroe isles had the lowest mean values; this is especially pronounced for those obtained on the two north-eastern isles Kunoy and Fugloy, where type 1 specimens accounted for $50 \%$ of the total male material. The differences in mean forewing lengths between types 1, 2 and 3 were analyzed with use of an ANOVA test and a nonparametric Mann-Whitney test, which in both cases showed significant differences. The p-value between type 1 and 2 was $<0.05$, and between type 1 and $3<0.01$. In the male material from Stora Dimun the samples of type 2 and 3 , and also the female samples, had smaller forewing lengths compared with the corresponding samples from 


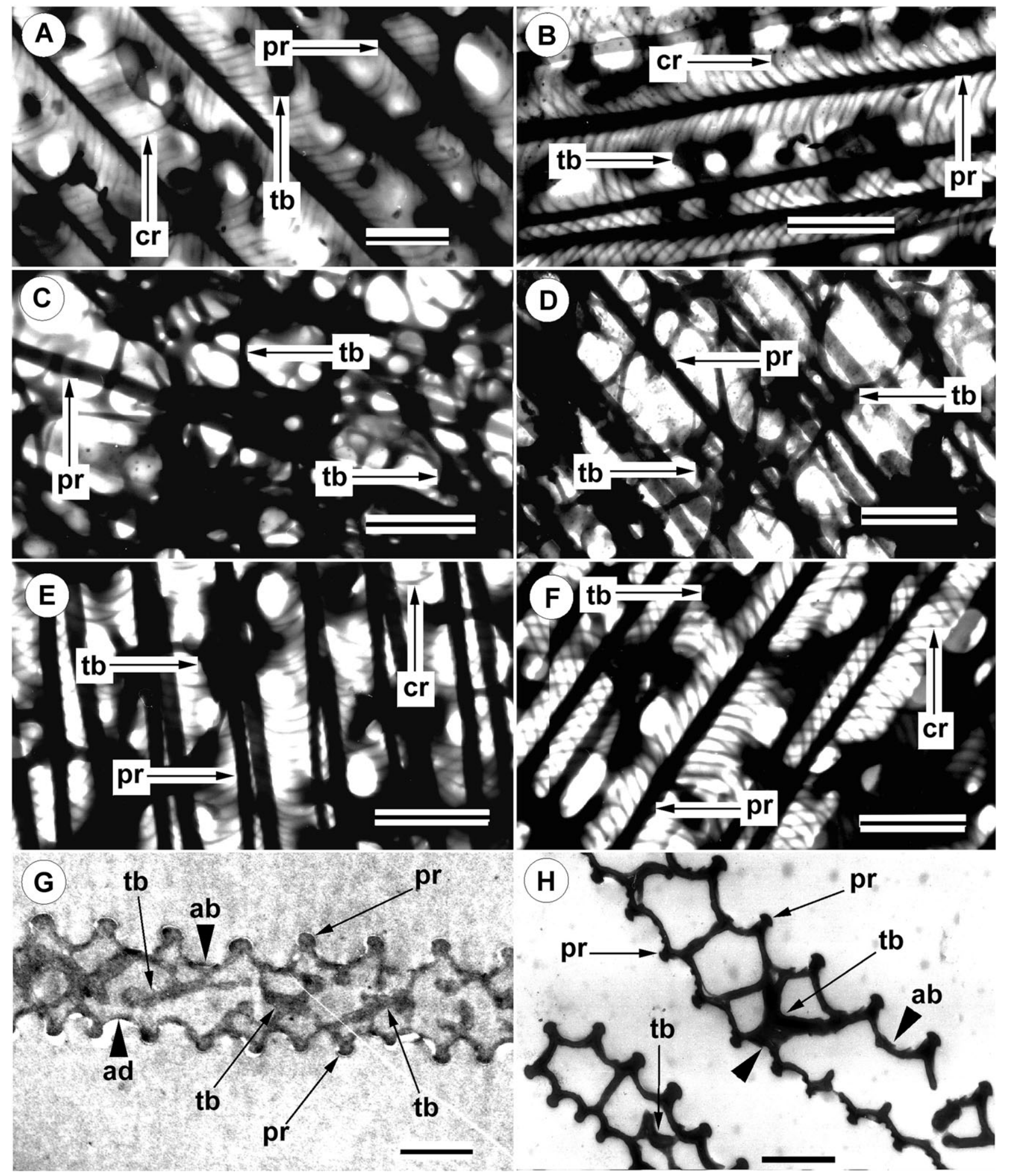

Fig. 5. H. humuli scales, TEM images. A-F: Whole mounts. Scale long axes are variably oriented, as were the scales themselves on the preparation support film; the axis is near-vertical in E, near-horizontal in B-C, and pronouncedly oblique in A, D and F. G-H: Transverse sections. A, B: H. h. humuli, female. A - forewing scale; B - hind wing scale. C, D: H. h. humuli, male. C - forewing scale; D - hind wing scale. E, F: H. humuli thulensis, type-3 male. E - forewing scale; F - hind wing scale. G - H. h. humuli, male, forewing scale. $\mathrm{H}-H$. humuli thulensis, type-3 male, forewing scale. ab - abwing scale wall; ad - adwing scale wall; $\mathrm{cr}-\mathrm{crossrib}$; $\mathrm{pr}$ - primary ridge; tb - trabecula. Scale bars: $1 \mu \mathrm{m}$. 
TABLE 1. Geographical variation in morph frequency and size in Hepialus humuli thulensis. Mean (in mm) and standard deviation (SD) of forewing length. M1, M2, M3: male types 1, 2 and 3; F: females. Separate listing of pooled data for major Faroe Isles (MaFIs) and Shetland (Shet), as well as of three consecutive annual samples from the Faroe island Stora Dimun (StDi). Faroe localities listed: Sumba, Trongisvagur (Su-Tr); Mykines (Mykin); Vagar: Midvagur (Va-Mi); Sandoy: Sandur (Sa-Sa); Nolsoy: Bygdin (No-By); Torshavn-Hoyvik (To-Ho); Eysturoy: Kalbak, Eidi (Ey-KE); Bordoy: Klaksvik (Bo-K1); Kunoy: Bygdin (Ku-By); Vidoy: Vidareidi (Vi-Vi); Fugloy: Kirkja (Fu-Ki).

\begin{tabular}{|c|c|c|c|c|c|c|c|c|c|c|c|c|c|}
\hline & \multirow{2}{*}{$\frac{\text { M 1-3 }}{\mathrm{N}}$} & \multicolumn{3}{|c|}{ M1 } & \multicolumn{3}{|c|}{ M2 } & \multicolumn{3}{|c|}{ M3 } & \multicolumn{3}{|c|}{$\mathrm{F}$} \\
\hline & & $\mathrm{N}$ & Mean & SD & $\mathrm{N}$ & Mean & SD & $\mathrm{N}$ & Mean & SD & $\mathrm{N}$ & Mean & SD \\
\hline \multicolumn{14}{|l|}{ MaFIs } \\
\hline $\mathrm{Su}-\mathrm{Tr}$ & 28 & 6 & 22.9 & 2 & 11 & 22.8 & 2.2 & 11 & 22.9 & 2.6 & 10 & 24.3 & 2 \\
\hline Mykin & 2 & & & & & & & 2 & 22.4 & 2.5 & & & \\
\hline Va-Mi & & & & & & & & & & & 4 & 23.9 & 1.6 \\
\hline $\mathrm{Sa}-\mathrm{Sa}$ & 29 & & & & 8 & 23.3 & 2.6 & 21 & 23.7 & 1.7 & 18 & 25.8 & 2.5 \\
\hline No-By & 9 & 2 & 21.6 & 1.3 & 6 & 24.5 & 1.7 & 1 & 24 & & 12 & 27.2 & 3.2 \\
\hline То-Но & 26 & 6 & 23.2 & 2.4 & 10 & 23.2 & 1.8 & 10 & 23.9 & 2.8 & 31 & 26.2 & 2.6 \\
\hline Ey-KE & 62 & 8 & 21.3 & 1.4 & 20 & 21.5 & 1.4 & 34 & 22.2 & 2.2 & 4 & 23.8 & 2.2 \\
\hline Bo-K1 & & & & & & & & & & & 1 & 26.8 & \\
\hline Ku-By & 24 & 12 & 22 & 1.3 & 9 & 23 & 1.6 & 3 & 22.8 & 1.7 & 30 & 25.8 & 3 \\
\hline Vi-Vi & 7 & 1 & 22.7 & & 3 & 22.1 & 2 & 3 & 22.6 & 0.2 & $\mathrm{a}$ & 23.8 & \\
\hline $\mathrm{Fu}-\mathrm{Ki}$ & 30 & 15 & 21.5 & 1.4 & 7 & 23.4 & 1.5 & 8 & 22.8 & 2.3 & 4 & 25.6 & 1 \\
\hline Total & 217 & 50 & 22 & 1.6 & 74 & 22.8 & 1.9 & 93 & 22.9 & 2.3 & 115 & 25.8 & 2.7 \\
\hline \multicolumn{14}{|l|}{ StDi } \\
\hline 1994 & 57 & 45 & 22.4 & 1.8 & 9 & 22.4 & 1.3 & 3 & 22.3 & 1.2 & 11 & 23 & 1.7 \\
\hline 1995 & 207 & 166 & 22.2 & 1.2 & 24 & 22.4 & 1.3 & 17 & 22.5 & 1.2 & 39 & 25.3 & 1.7 \\
\hline 1996 & 14 & 8 & 23.4 & 1.3 & 4 & 21.1 & 1.1 & 2 & 22.1 & 0.9 & 12 & 25.2 & 1.4 \\
\hline Total & 278 & 219 & 22.3 & 1.4 & 37 & 22.3 & 1.3 & 22 & 22.5 & 1.2 & 62 & 24.9 & 1.8 \\
\hline \multicolumn{14}{|l|}{ Shet } \\
\hline Unst & 10 & & & & 1 & 22.2 & & 9 & 22.5 & 1.9 & 3 & 25.1 & 1.8 \\
\hline Main & 11 & & & & 3 & 23.3 & 2.3 & 17 & 23.3 & 1.9 & 4 & 25.7 & 1.6 \\
\hline Total & 21 & & & & 4 & 23 & 2.3 & 17 & 23.3 & 1.9 & 4 & 25.7 & 1.6 \\
\hline
\end{tabular}

the larger Faroe isles, and the differences between the types were not statistically significant. The female samples in the three groups in Table 1 have greater forewing lengths than males, ranging from 2.4 to $2.9 \mathrm{~mm}$, which was significant at $\mathrm{p}<0.01$.

\section{DISCUSSION}

\section{Scale structure and evolution}

Sexual dimorphism in the wing scale morphology in continental $H$. h. humuli is prominent. Female scale structure in $H$. h. humuli is unexceptional for an exoporian moth; the colouration is due to pigmentation as in most hollow scales. In contrast, the male upperside scales with their colourless cuticle and elaborate meshwork of highly irregular internal reflecting surfaces have exactly the kind of specialised structure which could be expected to produce the brilliant white colour characteristic of this ghost moth par excellence. The absence or very weak development of scale dimorphism $/ 2^{\text {nd }}$ order ridges on many of the wing-surface scales in most examined males of $H$. humuli (some "type 3" specimens excepted) is unusual for a hepialid moth; however, it is paralleled on scales in silvery- white bands/spots on the wings of some other examined members of the family, and on all wing-surface scales (even ordinary, pigmented ones) in a few taxa such as Andeabatis (Simonsen, 2001).

The adwing lamellae of lepidopteran scales have been believed to be generally featureless. However, the presence of prominent primary ridges and other sculptural elements on this lamella has now unexpectedly proved to be of frequent occurrence on scales in the Exoporia, so there is nothing extraordinary about their presence on some scale types in $H$. humuli; they have similarly been observed in scattered members of other lineages among the lower Myoglossata (Simonsen, 2001). Also, while apically dentate (cover) scales are prevalent in the lower Neolepidoptera, pigmented scales with a smoothly rounded apical margin are recurrent in the (usually unilayered) wing vestiture of Hepialidae (Simonsen, 2001).

While the principal male morphs of Faroese $H$. humuli thulensis do exhibit some differences in scale structure, this does not at all account for the macroscopic polymorphism. All Faroese males investigated have the scale vestiture more similar to that of nominotypical males, rather 
than to that in nominotypical or Faroese females. Noteworthy similarities are the scale shapes (broader and generally more obtuse than in females), the more limited occurrence of scales with secondary $/ 2^{\text {nd }}$ order ridges, the dense hind wing coverings, the generally well developed ridges on the ventral lamella (apical area excepted), and the elaborate trabecular meshworks. Even the "female coloured" grey-brown hind wing scale coverings of type-3 $H$. humuli thulensis males are structurally overall similar to the specialised vestiture of $H$. h. humuli males.

The wing scale structure thus clearly supports the notion that the polymorphic male morphs in the $\mathrm{N}$. Atlantic islands have evolved from the monomorphic male type prevalent on the European continent/mainland Britain. In other words, contrary to Hoffmeyer's abovementioned suggestion the insular female-like male morphs do not represent the ancestral form; instead their pigmentation pattern represents a reversal, surely due to a switching on of genes that have remained silent during the recent evolution of the species in its main range. Expectedly morphs which are preponderant in some populations of a species should sporadically occur also in other populations, and indeed occasional female-like $H$. humuli males have been reported from Scotland (Heath, 1976). Also, on historical grounds it would not be expected that the N. Atlantic populations could have retained an ancestral pattern, since they must have been founded by relatively very recent post-Pleistocene immigrations from main-range stocks (see Brochmann et al., 2003 for a review of recent N. Atlantic biotic history). $H$. humuli, like most hepialid moths, shows little tendency to migratory behaviour, hence arrivals of immigrant mated females to the N. Atlantic isles (Faroes in particular) must have been very rare events, and the evolution of the distinctive male morphs was likely accelerated by negligible gene flow from main-range populations.

Some sexual dimorphism in forewing pattern is commonplace within the Hepialidae, but the dimorphism of H. h. humuli is unique. Hepialus is a monobasic genus in current hepialid systematics, and its closest relationships are unknown (its position adjacent to the Nearctic genus Sthenopis Packard, 1865 ["1864"] in the Exoporia checklist by Nielsen et al., 2000 may or may not prove to reflect its affinities correctly; a genuine phylogenetic analysis of the hepialid genera still remains to be done). In any case, the female forewing pattern appears unexceptional in the family; it is the unicolorous, shiningly white male which has no counterparts.

\section{Ghost moth visibility, sexual behaviour and predation pressure: a review}

Geographical trends towards higher frequency of darkened morphs have been observed in a number of moth species in NW Europe, and the particularly extensive observations of the phenomenon in the British Isles have been reviewed by Kettlewell (1973) and later Majerus (1998). Trends identified include increasing preponderance of darkened morphs towards areas with high rainfall ("pluvial melanism") and towards (in the British Isles primarily western) coastlines. The explanations invoked here are primarily (in the case of open-habitat crepuscular/nocturnal taxa - to which thermal effects of melanism may be negligible) enhanced crypsis of resting moths against darkened backgrounds. While such phenomena may indeed at some level promote melanism in the N. Atlantic $H$. humuli, the darkened morphs of this species were plausibly assigned to the category of "northern latitude melanism" which (again in the case of open-habitat crepuscular/nocturnal taxa) is attributed primarily to the extended twilight activity of predatory birds, and in the case of the males to a dramatic shift in the balance between selective agents favouring, respectively, visibility to sexual partners and invisibility to visually hunting predators. Already Ford (1955) had discussed the importance of the sexual signalling of the males' white uppersides that render them "conspicuous objects and attract the attention of the females, which fly to them". It is well known that in certain hepialid lineages including Hepialus the repertoire of sexual signalling comprises, in addition to the visual stimuli from lekking males, also pheromones emitted from their hind tibial brushes. The two are believed to act synergistically, perhaps "with long-range attraction mediated by means of pheromones, but with the visual attraction to the white males taking over at close range" (Mallet, 1984). Field observations in Shetland have shown that both types of sexual signalling are active in the mating process of $H$. $h$. thulensis (Kettlewell, 1973, citing observations by J.C. Cadbury), and it will be of particular interest to obtain more substantial data bearing on the "anecdotal evidence" (Majerus, 1998: 178) that pheromone attraction of these northern males is stronger than that of mainland males.

Andersson et al. (1998) provided interesting support for the theory that the silvery white coloration of $H . h$. humuli has evolved as a result of sexual selection: the lekking silvery white males are more visible to the females than more dull-coloured female-like males would be. Swarm initiation in male $H . h$. humuli exhibits a remarkably precise timing (documented already by Mikkola, 1974) in response to a decrease in ambient illumination below a certain critical level. Andersson et al. (1.c.) found that at their study site in Southern Sweden the males' display flight lasted no longer than 20-30 min, and that its onset approximately coincided with the time when there was an abrupt increase (due to changing spectral composition of ambient light) in the contrast between the moths' wings and the vegetation background. The lekking behaviour most likely owes its short duration to constraints imposed by predators: the briefness minimises encounters with birds and other visual hunters, which largely have ceased activity by the time in question. It also minimises encounters with early-emerging (largely "aerial-hawking") bats, and it leads to avoidance of lateflying (largely "gleaning") bats (Andersson et al., 1998; Rydell, 1998). It must be noted, however, that there are occasional records from S. Scandinavia of large aggregations of $H$. h. humuli males swarming until 2:00 a.m. (Carolsfeld-Krause, 1959). Records of occasional, even strong, dawn flights in mainland Britain, particularly 
"after a rainy spell of weather" (Koryszka, 1989), deserve to be followed up; are they a more regular phenomenon than so far recognized?

Ford (1955) had explained the presence of female-like males in Shetland by the high ambient light intensity at the moth's swarming time at high latitudes, when "...the night is never dark, so that selection no longer operates in favour of their conspicuous coloration; hence the breakdown which occurs there in the otherwise adaptive dimorphism". It is noteworthy, however, that although the range of $H$. humuli in continental Fennoscandia extends to ca $65^{\circ} \mathrm{N}$ (Nordström et al., Freina \& Witt, 1990), i.e., further north than the Faroe Isles, the males here remain monomorphic white right up to the northern range limit. Therefore, while the effect of light regime on females' capacity of partner finding remains one plausible cause for the breakdown of sexual dimorphism in the North Atlantic islands, it cannot alone explain the phenomenon. It seems likely that this effect is synergistic with a perhaps more important effect of a shift from bat predation to bird predation, i.e., from primarily non-visual hunters to visual hunters, as the principal selective agent acting on the adult moths.

In N. Europe gulls and terns may be the only birds that could be of importance as predators on the dusk-active ghost moth, and that importance undoubtedly decreases somewhat as one move inland in continental Fennoscandia. Andersson et al. during their field work in southern Sweden observed just a single episode where displaying male moths were strongly preyed on by common gulls (Larus canus); they also noted that other naturalists have reported on gull predation on the species. While incidences of bird predation appear to be occasional only, it was observed (also Rydell, 1998; Jensen et al., 2001) that leks of these large atympanate moths were consistently exploited heavily by early-emerging "aerial-hawking" bats, which may even use visual cues in their detection (Rydell \& Eklöf, 2003). A number of bat species, including early-emerging ones, occur throughout the range of $H$. humuli in continental Fennoscandia. In contrast, no bats are native in the Shetland or Faroe Isles (Baagøe \& Bloch, 1994; Mitchell-Jones et al., 1999).

In Shetland the common gull (Larus canus) and the blackheaded gull (Larus ridibundus) are well-known predators at the lek sites (Kettlewell, 1973). On the Faroes several other seabirds as arctic terns (Sterna paradisaea), herring gulls (Larus argentatus) and lesser blackbacked gull (Larus fuscus) are also recognized predators on several local lek sites (Dahl, 1954; Hansen \& Jensen, 2005). Field observations by SK on the Faroes from 1990 to 1998 indicate that most local lek sites only contained a small number of males, ranging from 10 to 50 with a swarming period up to $30 \mathrm{~min}$, during which the light coloured males are clearly visible in the dwindling light. On calm nights, often following adverse meteorological conditions with a delayed hatching of the moth, large aggregations of males are sometimes seen, such as on July 3 in 1997 on Sandoy, where the local lek site of about 2.5 acres close to the Atlantic ocean was literally covered by a living carpet of many hundreds, maybe thousands of males. The lek was heavily predated by a great flock of both common gulls and herring gulls which aggregated there shortly after sunset. The swarming commenced as usual at 35 min after sunset at 23:45 local time and went on past $01: 30$, when it was quite dark and the lek almost invisible to the human eye. The predation from the gulls ceased at about 01:00. As a corollary of the hypothesized bat-imposed constraints on swarming duration in continental $H$. humuli such long-lasting male display flights might be predicted to occur on the bat-free N. Atlantic Isles, but more observations bearing on the generality of this phenomenon are highly desirable, and in any case the effects will expectedly be to some extent offset by the prolonged activity of predatory birds, where these are abundant.

On other Faroe lek sites bird predation has been more casual from single gulls or even absent. This has been the case on two northeastern lek sites on Kunoy, and Kirkja on Fugloy with high abundance of light coloured male morphs of type 1 and 2 . In a general way high abundance of these light morphs is correlated with low intensity of bird predation, as also evident from the findings of Hansen \& Jensen (2005: Fig. 7). The relation is particularly clear in the large material available from Stora Dimun (Table 1 and data in Hansen \& Jensen, 2005) where bird predation is scored as "low" by Hansen \& Jensen; according to local naturalist Ms Kinna ur Dimun (pers. comm. to SK) the only breeding gull colonies on that islet were of the very common non-predatory kittiwake (Rissa tridactyla).

The smaller size of the light-coloured male morphs of type 1 compared with the darker type 2 and 3 morphs has apparently not earlier been recognized, probably due to the scarcity of type 1 morphs in Shetland. This difference may evidently be considered to support the importance of selection pressure from visual predators against male conspicuousness, but while statistically significant it remains uncertain whether it is sufficiently large to have any biological significance. Such significance could even have come in other forms, including higher manoeuvrability due to increased wing loading.

The flight season of $H$. humuli in the Faroes commences around solstice and lasts about five weeks. In a lek site on Nolsoy, Hansen \& Jensen (2005: 127 and Fig. 6) observed a shift in the proportional representation of the male morphs during this season, the dark coloured types 2 and 3 becoming successively more abundant. Further inquiries into the regularity of such temporal morph frequency shifts are highly desirable. If recurrent, do they reflect predators' proportionally higher successive elimination of the lightest morphs, changing predator behaviour during the weeks in question, or both? Obviously additional field observations are needed.

ACKNOWLEDMENTS. We are grateful to L. Aarvik (Zoologisk Museum, Oslo), Hans Baagøe (Natural History Museum of Denmark, Copenhagen University), D. Carter (formerly Natural History Museum, London), K. Mikkola (Naturhistoriska Centralmuseet, Helsinki), C. Rahbek (Biological Institute, Copen- 
hagen University), and N. Ryrholm (University of Gävle) for useful information. Ms Kinna ur Dimun provided the 1994 and 1995 samples from Stora Dimun. Peter Gjelstrup (Museum of Natural History, Århus) and Cino Pertoldi (Institute of Biology, University of Århus) assisted SK with statistics. J.T. Høegh (Biological Institute, Copenhagen University) assisted TJS with the transmission electron microscopy. G. Brovad (Natural History Museum of Denmark, Copenhagen University) photographed the moth specimens. SK's fieldwork in the Faroe and Shetland Isles was supported by the Carlsberg Foundation, the University of Århus, Natural History Museum, Århus and Faroese Museum of Natural History. TJS was supported by a postdoctoral grant from the Carlsberg Foundation and an NSERC Discovery Grant (to postdoctoral advisor F.A.H. Sperling) while the manuscript was completed.

\section{REFERENCES}

Andersson S., Rydell J. \& Svensson M.G.E. 1998: Light, predation and the lekking behaviour of the ghost swift Hepialus humuli (L.) (Lepidoptera: Hepialidae). Proc. R. Soc. Lond. (B) 264: 1345-1351.

BAAgøE H. \& Bloch D. 1994: Bats (Chiroptera) in the Faroe Islands. Fródskaparrit 41: 83-88.

Brochmann C., Gabrielsen T.M., Nordal I., Landvik J.Y. \& ELVEN R. 2003: Glacial survival or tabula rasa? The history of North Atlantic biota revisited. Taxon 52: 417-450.

Carolsfeld-Krause A.G. 1959: The mating of Hepialidae (Lep.). Entomol. Rec. J. Var. 71: 33-34.

DAHL L. 1954: Firvaldur i Føroyum [Lepidoptera of the Faroes]. Frodskaparrit 3: 128-154.

DE Freina J.J. \& WitT T.J. 1990: Die Bombyces und Sphinges der Westpalaearktis 2. Forschung und Wissenschaft, Munich, $143 \mathrm{pp}$.

DowneY J.C. \& Allyn A.C. 1975: Wingscale morphology and nomenclature. Bull. Allyn Mus. 31: 1-32.

FoRD E.B. 1955: Moths. Collins, London, 266 pp.

Hansen J. \& Jensen J.-K. 2005: Colour morphs of the ghost moth Hepialus humuli L. (Lepidoptera, Hepialidae) in the Faroe Islands. Entomol. Medd. 73: 123-130.

Heath J. 1976: Hepialidae. In Heath J. (ed.): The Moths and Butterflies of Great Britain and Ireland 1. Blackwell Scientific Publications/Curwen Press, London and Oxford, pp. 166-170.

HoffMeyer S. 1948/1960: De Danske Spindere. 2nd ed. Universitetsforlaget, Århus, 194 pp.
Jensen M.J., Miller L.A. \& Rydell J. 2001: Detection of prey in a cluttered environment by the northern bat Eptesicus nilssonii. J. Exp. Biol. 204: 199-208.

Kettlewell B. 1973: The Evolution of Melanism. The Study of a Recurring Necessity. With Special Reference to Industrial Melanism in the Lepidoptera. Clarendon Press, Oxford, 423 pp.

KoRYSZKA J. 1989: An observation on the dawn flight of the ghost moth. Bull. Amat. Entomol. Soc. 48: 114.

KRISTENSEN N.P. \& SimONSEN T.J. 2003: 'Hairs' and scales. In Kristensen N.P. (ed.): Lepidoptera: Moths and Butterflies 2. Handbuch der Zoologie/Handbook of Zoology IV/36. Walter de Gruyter, Berlin and New York, pp. 9-22.

LORIMER R.L. 1983: The Lepidoptera of the Orkney Islands. Classey, Faringdon, 103 pp.

Majerus M.E.N. 1998: Melanism. Evolution in Action. Oxford University Press, Oxford, New York, Tokyo, 370 pp.

MaLLET J. 1984: Sex roles in the ghost moth, Hepialus humuli (L.) and a review of mating in the Hepialidae. Zool. J. Linn. Soc. 80: 67-82.

Mikкola K. 1974: Timing of swarming in Hepiolus humuli L. (Lep., Hepialidae): a summary. Entomol. Medd. 42: 76-77.

Mitchell-Jones A.J., Amori G., Bogdanowicz W., Kryštufek B., Reijnders P.J.H., Spitzenberger F., Stubbe M., Thissen J. B.M., Vohralík V. \& Zima J. (eds) 1999: The Atlas of European Mammals. Poyser (for the Societas Europaea Mammalogica), London, $484 \mathrm{pp}$.

Nielsen E.S., Robinson G.S. \& Wagner D.L. 2000: Ghostmoths of the world: a global inventory and bibliography of the Exoporia (Mnesarchaeoidea and Hepialoidea) (Lepidoptera). J. Nat. Hist. 34: 823-878.

RYDELL J. 1998: Bat defence in lekking ghost swifts (Hepialus humuli), a moth without ultrasonic hearing. Proc. R. Soc. Lond. (B) 265: 1373-1376.

RYDELL J. \& EKLÖF J. 2003: Vision complements echolocation in an aerial-hawking bat. Naturwissenschaften 90: 481-483.

SiMONSEN T.J. 2001: Wing vestiture in non-ditrysian Lepidoptera (Insecta). Comparative morphology and phylogenetic implications. Acta Zool. 82: 275-298.

SkInNER B. 1984: Colour Identification Guide to Moths of the British Isles. Penguin, Harmondsworth, 267 pp.

South R. 1961: The Moths of the British Isles. 4th ed. Frederick Warne, London and New York, $\mathrm{x}+595 \mathrm{pp}$.

Received December 18, 2008; revised and accepted February 24, 2009 